\title{
POTENTIAL INTEGRATED SMART WASTE SEGREGATION FOR ALL STAKEHOLDERS
}

\author{
BARMAK SADRI ${ }^{1}$, BARAT ALI KHAKPOOR ${ }^{2} \&$ MOHAMMAD AJZA SHOKOUHI $^{2}$ \\ ${ }^{1}$ Faculty of Economics and Administrative Sciences, Ferdowsi University of Mashhad, Iran \\ ${ }^{2}$ Department of Geography, Ferdowsi University of Mashhad, Iran
}

\begin{abstract}
There are formal and informal recycling workers as a part of the mainstream and resource management system that are handling separation of waste at source duties instead of urban dwellers who are facing the loss of aesthetic value of their cities. Less recycling wastes remain in the strewed waste bins to serve a circular economy from this disgusting perspective where uncontrolled waste collection, recycling, treatment, and disposal is likely to have health impacts on such workers. Further, their operations cause dispersal of contamination and debris that do not sound effective and environmentally waste management for a clean city and a pleasant and healthy living environment that is attractive to residents and visitors. The increasing number of informal workers demonstrates unsuccessful strategies of separation of waste at source and aborted due to lack of citizens engagement. Recently smart technologies emerged that sound useful to tackle the issues due to its capabilities of monitoring waste stream. Hence, the investigated performance indicators by scholars to improve waste management, reviewed in this study to develop a model for smart waste recycling. The service design approaches employed to be compatible to local infrastructures of the studied cities of Tehran and Mashhad in Iran that the potential smart waste segregation model figured out, based on integrated smart identification of all stakeholders, to apply legislation for citizens, communities and advocates, and private sector, and to provide monitoring and measurement tools about recycling waste and 4R (reduction, reuse, recycling, recovery) procedures. The system could be implemented in similar metropolises like Ankara, who face such issues. Further local analysis for technology acceptance evaluation should apply to refer client types, generation, and local infrastructures whether a combination of different identification and pickup methods will meet their satisfaction and improve the waste management system.

Keywords: informal recycling workers, separation of waste at source, monitoring waste stream, integrated smart waste recycling, smart waste identification, potential smart waste segregation system, disgusting perspective of cities, SAAS, DSS, circular economy.
\end{abstract}

\section{INTRODUCTION}

The world's urban population has grown rapidly from 751 million to 4.2 billion in 2018 [1]. It expects to increase by $25 \%$ by 2050 , Leading to a global population of 9.8 billion [2]. Now more than ever, cities are hot spots that threaten global ecological boundaries. Hence global sustainability pivots mainly on cities and that meeting this challenge requires an urgent change in urban policymaking and planning (Olazable and Pascual [3]). Therefore, we are facing lots of issues in our daily life in the cities as urban dwellers. The increasing volume and complexity of waste associated with the modern economy is posing a serious risk to ecosystems and human health [4]. Adequate and affordable solid waste collection services sound accessible in metropolises of Iran for citizens, where have been facing numerous informal waste workers in the recent decade due to failing separation at source strategies. There are remaining recycling waste management kiosks from previous management that still provide barter products instead of transferring all their clients' waste to the informal workers where they are accessible around every single waste bin.

A practical and environmentally waste management where contributes to a clean city, and a pleasant and healthy living environment needs urgent collaboration of both citizens and management to tackle informal workers issue. Fortunately, expanding digital technologies 
introduce new signs to struggle with complicated challenges like separation of waste at source during a scientific journey to figure out a potential smart waste segregation system that would be based on any further complementary research. What are the indicators of a potential smart waste segregation system for Tehran and Mashhad's target cities to engage all citizens that would be compatible with available infrastructure?

The aim of the research addresses the objective of minimizing the informal workers by maximizing the participation of citizens in the separation of waste at source, or less informal supply concludes less informal demand.

There is an urgent need to look into the issues of SWM and improve city leaders' ability to manage with shrinking budgetary support. Performance indicators (PIs) are measurement tools used by organizations to evaluate the success or failure of a given activity. He conducted a holistic review of articles to develop performance indicators for municipal solid waste management after analyzing 387 research papers published in the area of solid waste management (SWM) (Sanjeevi and Shahabudeen [5]). The initial SWM models were optimization models, and most dealt with minimizing costs (Berger et al. [6]). There were developments of new models by researchers as [7]-[10], with increasing complexity in SWM in the cities of the developing world, selection, or setting up of an optimum SWM system becomes difficult for technical and operation research professionals. Researches led to the use of various mathematical models and systems analysis techniques to develop integrated solid wastes management systems. By focusing on the application of general management techniques, the research papers grouped under various types in a flowchart makes it easier to understand the nature of SWM systems .Also, the authors grouped the papers for each decade under the 18 different types, such as cost reduction, optimization, reports/guidelines, and legislation. Then modern productivity tools like research focusing on the introduction of GIS/GPS, RFID, barcodes, and their implications in improving SWM via DSS, which started to appear only since 2000, synchronized with the commercial arrival of these technologies.

Further inferences from flowchart for the field research are characteristic of SWM issues and challenges in various cities, Models based on real-life case studies, current standards of SWM, and life cycle assessment. These would be researched this study by evaluating for recycling waste management. The challenge is separation at source by citizens to struggle with informal worker increment in Tehran and Mashhad. Our model, based on real-life case studies, compares the current facilities of recycling waste management services (consists of formal recycling workers by vans and recycling kiosks). To find out covert elements of the smart system, whether it is service or decision support system (DSS). A service-based smart system sounds more compatible with an integrated system by software as a service or SAAS system.

Armijo et al. [11] incorporated vital requirements such as social participation, social perception, and communication levels like those of the PIMS for the first time. They designed a driving force-pressure-state-impact response (DPSIR) model, involving 18 indicators like coverage, generation, composition, and efficiency. They also suggested that a user-friendly tool, which captured the complexity of the SWM, be developed. The performance criteria detailed by indicators such as the percentage of citizens in favour of recycling and those complying with the government regulations might not require from the PI's point of view. Nevertheless, in the interest of this study, a user-friendly tool considers generation and composition or different types of potential smart waste segregation system customers in favour of recycling waste. Those should comply with government regulations. As demonstrated by Sanjeevi and Shahabudeen [5] the study with 5PIs includes social perception and social participation (only $0.4 \%$ ), which complies with the objectives of this study further suggested future research agenda for the future like community engagement where could 
have an important role in the improvement of recycling waste management, Maryono and Hasmantika [12] defined the high-level application of smart waste recycling with excellent community support. The provision of this application service must balance with socialization from the Government to the community. Hence, the mobile application facilitates communication between management and stakeholders in the era of digitization.as our platform is an integrated system. Therefore, the community acts should conduct into the system, and co-relation between citizens and communities would be possible to avoid any interruption in the data gathering process. Official data for MSW recycling often come from municipal governments, which in many developing countries focus on managing the MSW they collect (or which is collected on their behalf by the formal sector, leaving the collection of materials for recycling often to the informal sector). Official data, either at the city level or compiled from city-data by national governments, are thus likely to be under-reporting recycling rates (Wilson et al. [13]). The informal recycling that is often dominant in many developing countries is generally from mixed MSW. However, there can be a significant contribution from itinerant waste buyers who collect and pay for source-separated materials accumulated by householders or domestic servants. Community initiatives may also collect source-separated materials to gain funds for local charities (Wilson et al. [13]). Hence, the integrated smart system could be more useful for raising funds for local charities. In the worst case, $15 \%$ of citizens recycled waste in a month, which empowers charities to support the monthly wage of 5,000 informal workers according to the study despite waste management revenue from recycling waste. Segregation of MSW at source is critical to ensure that the waste separated into organic and dry recyclable fractions. Segregation of MSW at source, separating organic and dry recyclable fractions, is critical to avoid cross-contamination and to maintain the quality of the materials, which will lead to more effective recycling and divert waste from landfills. Further, segregated waste reduces health and safety-related risks to waste pickers and to the ecosystems around the waste treatment and disposal sites (Wilson et al. [13]). The issue addresses guidelines importance within smart system growth to lead better participation updated materials and illustration could affect the results. Economic instruments serve to steer stakeholders' behaviours and practices towards strategic goals through marketbased incentives and disincentives. For example, a pay-as-you-throw (PAYT) is a charging system for residual (mixed) waste. It rewards people for segregating their waste, taxes on landfilling or incineration will discourage opting for these methods; fiscal benefits will encourage private companies' investment in SWM (Wilson et al. [13]). Economic instruments, as the legislation drivers are desirable in the recycling waste system. The incentives indicator for delivering waste to any verified picker, even charities versus disincentives, charge more tax for citizens if they do not deliver recycled waste at least once a month. Refer to the introduction elements of the potential smart waste segregation figure out as a smart recycling waste model shown in Fig. 1.

The connectivity of the elements as the conclusion of the research method covered by several iterations is the indicator of Smart Identification.

\section{METHODS}

To find out the expected specifications of a potential smart waste segregation system for target cities of Tehran and Mashhad. By considering discussion that the system would use as a service or SAAS. The appropriate approach to propose a prototype of a system is the service design approach that exploring the qualitative study. So inductive button-up research implied via a journey map of the autoethnographic approach. "Real" (i.e., rather academic) autoethnographic research might involve researchers immersing themselves for months 


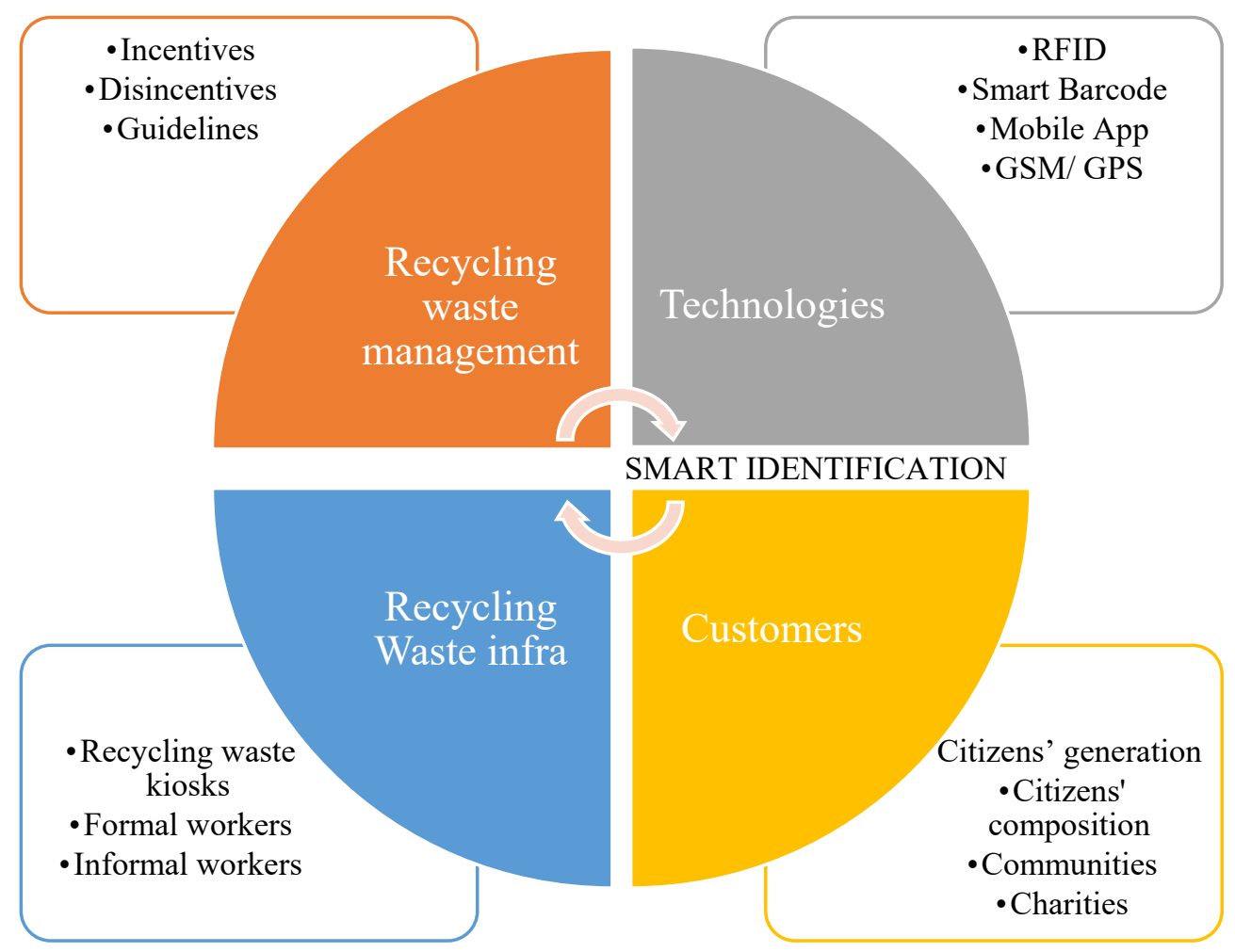

Figure 1: Smart waste stream identification.

within an organization. In service design, we often use a short version of this: team members explore a particular experience in the real situational context, mostly as customers or as employees. Autoethnography is often one of the first research methods undertaken as it helps researchers to interpret behaviours they will see when they observe participants. Also, it helps researchers to conduct interviews more efficiently and comprehensively when they already have a rough understanding of the subject matter. Hence, in this study, the author explored a particular experience of it self-document this using field notes, photographs, and both covert and overt interviews depend on conditions to avoid observer effect (Stickdorn et al. [14]).

\subsection{Material}

To analyze waste collection services of target cities, a simple persona between different generation and composition selected as a single middle age customer where produces an average amount of recycling waste per person. The journey of how it can deal with recycling waste describes the interrelation of recycling waste picker with the customer, and how waste 
pickers damage the aesthetic perspective of daily urban life despite dispersal of contamination and debris within their operation.

\subsubsection{Persona}

The persona case (Fig. 2) faces with recycling workers around the bins, sometimes he delivers recycling waste to the recycling waste kiosk and got other products instead of the value of the waste or leave the waste cost to the kiosk, sometimes he delivers waste to the informal workers. Waste management collection service runs twice a day appropriately. The customer has no problem with waste collecting service, and He regularly throws the waste to the bins.

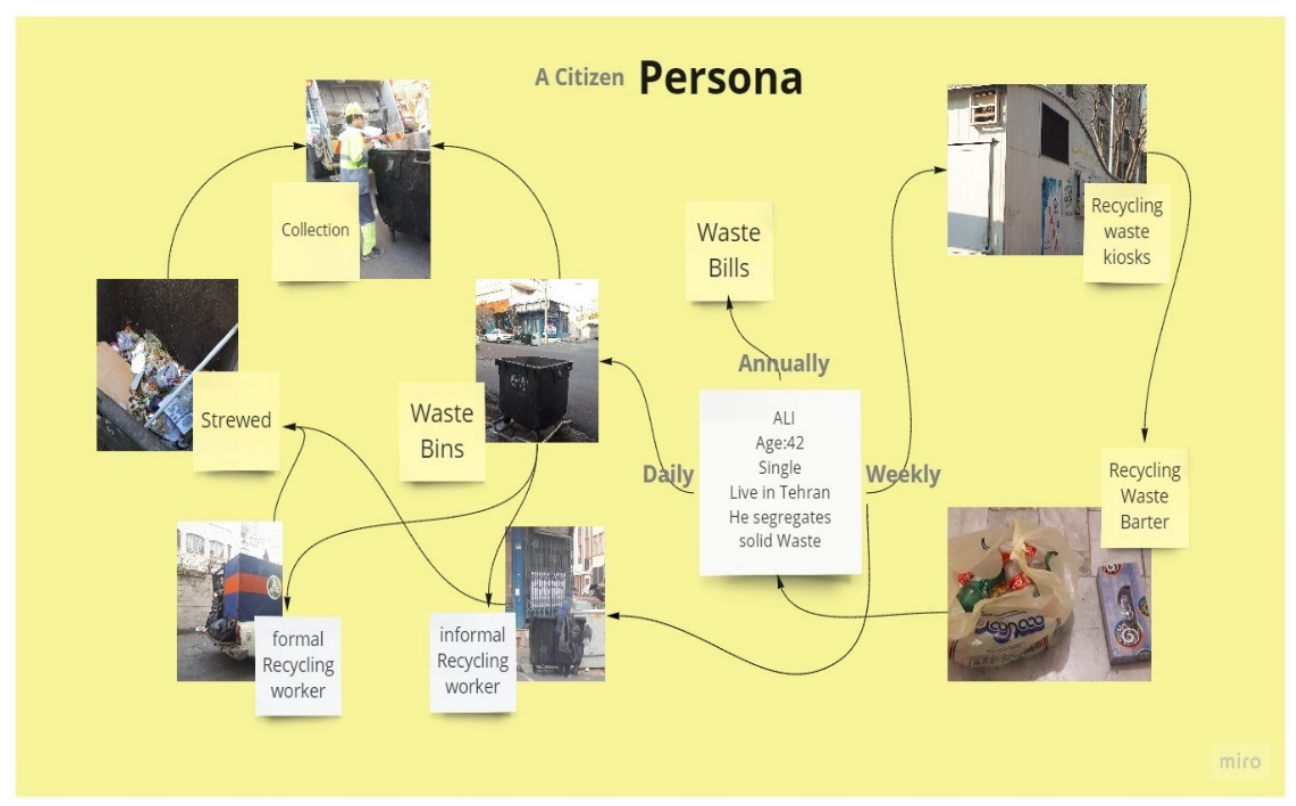

Figure 2: Citizen persona of waste tasks.

The waste management system has two stakeholders acting as recycling waste pickers, kiosks, and formal workers with pick-up where there is an allegation that some of the informal workers transfer their collected recycling waste to the formal workers. The issue is a conflict with other stakeholders as waste pickers who strew recycling waste from the bins cause an ugly image of the city.

\subsubsection{Retrospective challenges}

A retrospective analysis of what made a citizen MAD, SAD, and Glad mapped in Fig. 3 would bring some insights for understanding customer challenges. It segregates recycling waste, then delivers the recycling waste to the kiosk by car and must pick up barter goods instead of where the kiosk does not care about citizenship. The recycling waste workers made a disgusting perspective when strewing the bins for solid wastes. Their operations cause dispersal of debris and contamination due to mismanagement of recycling waste management. 


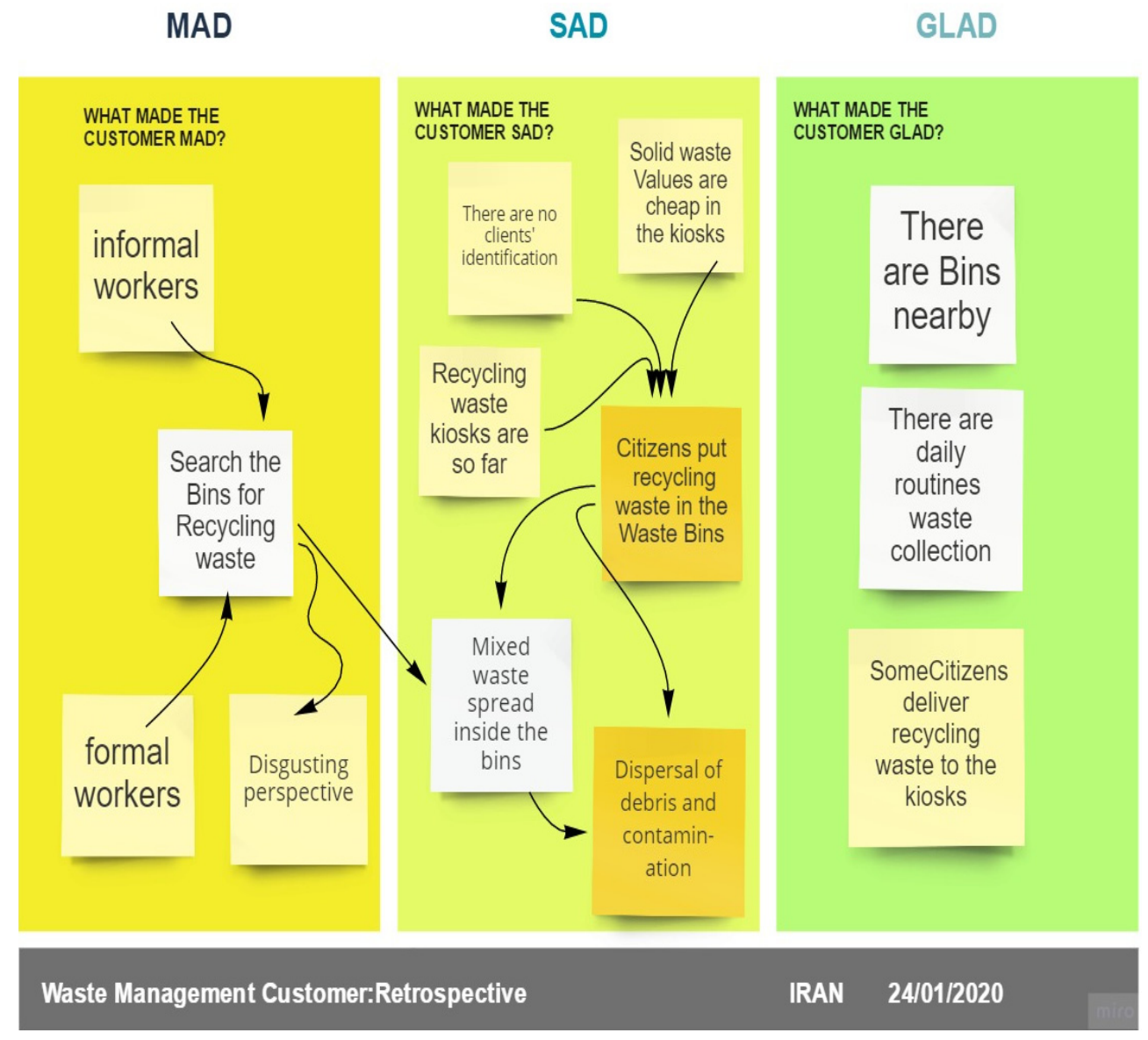

Figure 3: Customer retrospective.

\subsection{Pre-ideation}

Retrospective challenges develop some questions about the origin of the issue, whether those could lead us to find out a solution to tackle these challenges. Why have recycling workers expanded in the city? Due to the importance of the circular economy, economic conditions, illegal immigration, low participation of citizens at the separation of waste at source caused the abundant supply of recycling waste for workers. So, why do not more citizens participate in the separation of waste at source? Due to far facilities, Lack of obligation and no costbenefit motivation, and why do some citizens participate in the separation of waste at source? Due to cultural reasons, environmental worries, the life cycle of materials, charity intention, and saving the planet for the next generation.

Hence, the above concludes a few hypotheses as if a system could decrease the supply of recycling waste at the bins, then recycling waste working demand would decline if citizens' engagement increases at the separation of waste at source, the supply of recycling waste would decrease. Finally, appropriate obligations and facilities raise citizens' participation. 


\subsubsection{Case studies from overseas}

What kind of recycling waste collection systems has implemented to overcome the issues?

Case studies from overseas, from similar persona customer, from countries with less informal workers as demonstrated in Fig. 4 indicates that disincentives and guidelines incorporated as obligations by fines and cautions. It is plausible for waste management to apply obligations through the identification of customers by codes of the bins and RFID. Thus, identification addresses the system's key indicator.

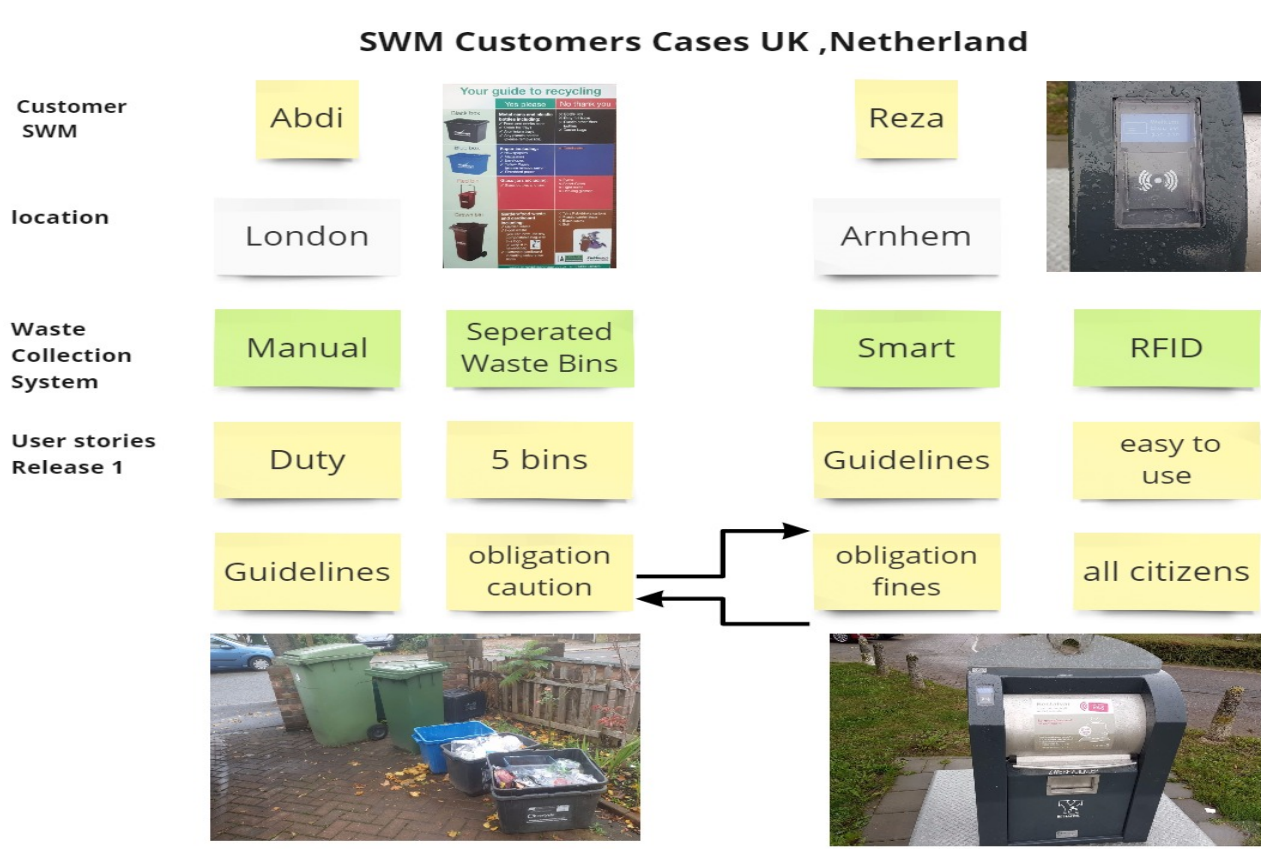

Figure 4: SWM Customers persona cases UK and The Netherlands.

Other criteria noticed by the Smart systems, although the further study of peer-reviewed articles, generally focused on smart waste collection systems by using different integrated methods for optimizing waste collection by container identification (Fig. 5) consisting of the control centre and bins sensors, IoT of bins, mobile application and more. This optimization applies to formal recycling workers with puck-up where should receive signals by customers instead of a container, however,

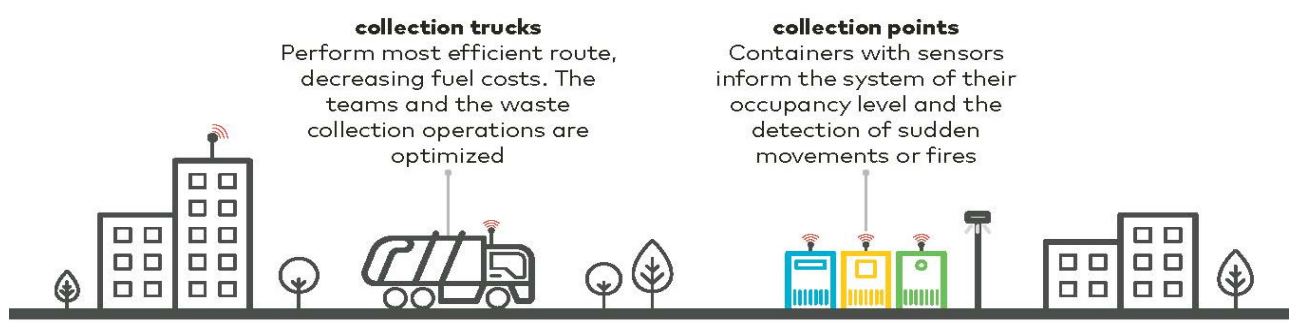

Figure 5: Smart waste collection system [15]. 
The technology case study demonstrates other features of smart systems usually used by the smart underground system; those identify customers by RFID, barcode bags, mobile applications and could measure and calculate incentives and disincentives. There are separate recycling waste inlets that customers throw their waste according to the guidelines. The underground network of tubes shown in Fig. 6 (left) is suitable for condense spatial parts of the cities where collection trucks could not drive in the alleys but needs costly infrastructure construction. The next one, Fig. 6 (right), digs the underground bins. It could be more compatible with the collection system consist of trucks and bins, even though it is still costly infrastructural operation for waste management, whether the cost of such systems could be affordable. Hence, the most critical issue of these systems is their cost of implementation. Despite the capability of the underground system to tackle objectives of this study like aesthetic perspective damaged by informal and formal recycling workers further avoiding dispersal of contamination and debris due to covered and unreachable bins and container as a holistic approach for separation at source and solid waste management system, but urgent action is a practical solution compatible to the current facilities.
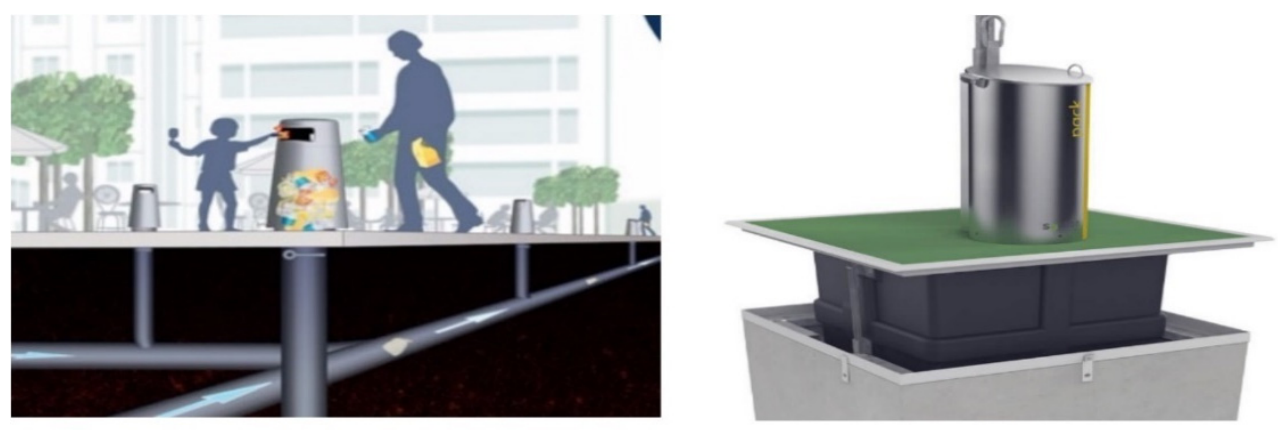

Figure 6: Smart waste bins solutions [16], [17].

\section{RESULTS AND DISCUSSION}

\subsection{Prototyping potential smart waste segregation system}

According to a comprehensive review during the journey map, adequate information reached to propose a prototype that connects elements of the smart recycling waste model as a service blueprint to adopt local facilities and gather offers. The smart improvement in local recycling waste services based on smart identification facilitates separation at source operation to struggle with current issues and concludes the objectives of the study. The cross interrelation of stakeholders addresses collaboration between recycling waste management and customers. The generation of customers covered by different types of identification makes it plausible for elder or youth generation to connect to the system despite composition, whether household or tradespeople. The community acts in the integrated system to avoid the extra cost to the system by identifying their advocate from the primary customer identification system. However, the system is capable of leading charity and donations inside the system, for example, transforming informal workers in the formal direction. The recycling waste management applies incentives and disincentives inside the system where indicates a condition that needs guidelines. However, this basic system adopts any further technology 
improvement in waste management infrastructure, hence avoid waste of resources and support waste management as a data tool for future analysis and research. Based on the smart identification, an affordable system developed by service blueprint shown in Fig. 7 as a model.

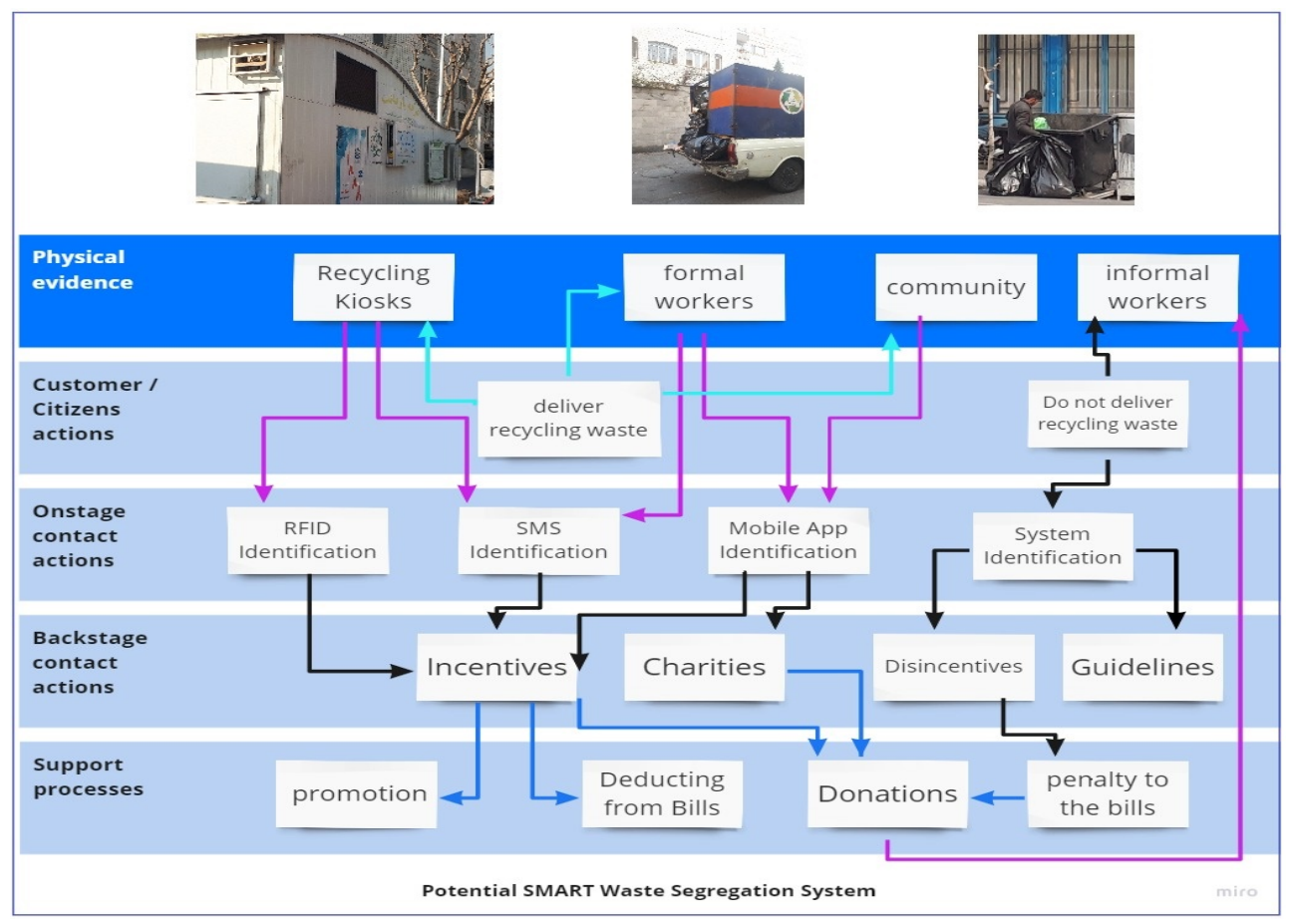

Figure 7: Potential smart recycling waste segregation.

\subsection{Next research agenda}

The current research is according to the analysis of customers' adaptation to the potential smart waste segregation system to identify the effects of the indicators on different aspects of Waste Management Dimensions environmental, economic and social where from Sanjeevi and Shahabudeen [5] point of view, in addition to two other political and administrative aspects, would be ideal for any city and simple enough for execution and performance evaluation and monitoring of an integrated SWM system. The proposed model demonstrates the administrative key role in developing a potential integrated system include system implementation, which followed by incentives, disincentive, and guideline application. Wherefrom the author's point of view, in the recycling waste system administrative aspect can merge to economic and social dimensions through incentives, disincentives, and guidelines. The political aspect evaluates inter-relation between different organizations that the issue could affect their boundaries like health and environmental organizations. Hence, any future research in this field can evaluate effective regulations and relation about the issue as agenda. 
Though the technology acceptance model agenda evaluates potential system any further research on the performance of a plausible implemented integrated system recommended by the authors, therefore, the complementary study includes other aspects like financial analysis and technology acceptance model to iterate and improve.

\section{CONCLUSION}

The evaluation of potential smart system leads the waste management system to develop a system for further analysis with appropriate data. Implementation of a preliminary potential smart recycling waste system service serves the administration to figure out the procedures of the decision support system (DSS). Nevertheless, both systems need to address initial technology for any future infrastructure development of waste management systems in the next phase.

The resources come from the potential integrated smart waste segregation system can transform recycling waste workers into the formal part of the recycling waste circle that deserve human dignity and remove disgusting aesthetic perspective from the cities.

Any cities that struggle with informal recycling issues need the implementation of a smart waste stream identification system for all stakeholders, which is the base of any future development. Without sufficient data from all customers, it cannot manage to achieve sustainable development goals. The system could implement in similar metropolises like Ankara who face such issues but needs further local analysis for technology acceptance evaluation refer to client types, generation and local infrastructures whether a combination of different identification methods will increase their satisfaction and improve waste management system or not.

\section{ACKNOWLEDGEMENT}

In memory of Dr A. Sedghi (GP) for the information provided who suffered badly from Covid-19 in London and died on 27 May 2020.

\section{REFERENCES}

[1] United Nations, $68 \%$ of the world population projected to live in urban areas by 2050 , says UN, 2018. www.un.org/development/desa/en/news/population/2018-revision-ofworld-urbanization-prospects.html.

[2] United Nations, World population projected to reach 9.8 billion in 2050, and 11.2 billion in 2100, 2017. www.un.org/development/desa/en/news/population/worldpopulation-prospects-2017.html.

[3] Olazable, M. \& Pascual, U., Use of fuzzy cognitive maps to study urban resilience and transformation, Environmental Innovation and Societal Transitions, 18, pp. 18-40, 2016.

[4] UN Environment Programme, Solid waste management, 2018. www.unenvironment.org/explore-topics/resource-efficiency/what-we-do/cities/solidwaste-management.

[5] Sanjeevi, V. \& Shahabudeen, P., Development of performance indicators for municipal solid waste management (PIMS): A review. Waste Management and Research, 33(12), pp. 1-14, 2015.

[6] Berger, C., Savard, G. \& Wisere, A., EUGENE: An optimization model for integrated regional solid waste management planning. International Journal of Environment and Pollution, 12(2/3), pp. 280-307, 1999.

[7] Gottingger, H.W., Economic Models and Application of Solid Waste Management, Gordon and Breach Science Publishers: New York, 1991. 
[8] Huang, G.H., Baetz, B.W. \& Patry, G.G., Grey dynamic programming for waste management programming under uncertainty. Journal of Urban Planning and Development, 120(3), pp. 132-156, 1994.

[9] Abou Najm, M., El-Fadel, M., Ayoub, G., El-Taha, M. \& Al-Awar, F., An optimization model for regional integrated solid waste management. 1: Model formulation. Waste Management and Research, 20(1), pp. 37-45, 2002.

[10] Abou Najm, M. \& EI-Fadel, M., Computer-based interface for an integrated solid waste management optimization model. Environmental Modelling and Software, 19(12), pp. 1151-1164, 2004.

[11] Armijo, C., Puma, A. \& Oieda, S., A set of indicators for waste management programs. 2nd International Conference on Environmental Engineering and Applications, Singapore, 2011.

[12] Maryono, M. \& Hasmantika, H., Preliminary study of smart urban waste recycling in Semarang, Central Java, Indonesia. Proceedings of the International Conference of Smart City Innovation 2018, 2019.

[13] Wilson, D.C. et al., Global Waste Management Outlook, United Nations Environmental Programme, 2015.

[14] Stickdorn, M. et al., This is Service Design Doing: Applying Service Design Thinking in The Real World, O'Reilly Media, USA, pp. 80-108, 2018.

[15] Citibrain, Value urban waste, 2019. www.citibrain.com/en/solutions/smart-waste/.

[16] Envac, 2019. www.envacgroup.com/.

[17] Sotkon Waste Systems, Intelligent systems, 2019. https://sotkon.com/en/intelligentsystems/. 